\title{
SOBRE LOS MODOS DE VISIBILIZACIÓN MEDIÁTICO-POLÍTICA DE LA VIOLENCIA DE GÉNERO EN ESPAÑA: CONSIDERACIONES CRÍTICAS PARA SU REFORMULACIÓN ${ }^{1}$ \\ REGARDING HOW GENDER VIOLENCE HAS BEEN MADE VISIBLE IN MEDIA-POLITICAL TERMS IN SPAIN: A CRITIQUE TOWARDS ITS RECONCEPTUALIZATION
}

\author{
María José Gámez Fuentes \\ Universitat Jaume I, Castellón, España \\ gamezf@uji.es
}

Recibido: 23/10/2012

Aceptado: 28/11/2012

\begin{abstract}
Resumen
El presente trabajo tiene como objetivo situar discusiones recientes que han focalizado en la visibilización mediática de la violencia de género en España atendiendo a presentarlas en relación, por un lado, a los ejes discursivos del marco de reconocimiento establecido y, por otro, a las implicaciones teóricopolíticas de este. Nuestra hipótesis es que la forma de visibilizar la violencia de género, en particular respecto de la judicialización como estrategia mediatizadora, no solo desactiva las posibilidades de transformarla sino que reproduce marcos de reconocimiento donde las mujeres no son sujetos agentes. El sujeto mujer configurado como víctima denunciante se encuentra supeditado al saber y control judicial y, por tanto, desprovisto de agencia. Para contribuir a la
\end{abstract}

\footnotetext{
${ }^{1}$ Agradezco a Eloísa Nos y Eva Espinar sus comentarios en la revisión de este artículo, a Daniel La Parra sus sugerencias bibliográficas y a Fabricio Forastelli su constante aliento intelectual.

La escritura de este trabajo ha sido posibilitada gracias a la subvención concedida por la Secretaría General de Universidades del Ministerio de Educación (referencia PR2011-0448) para realizar una estancia de investigación en la Universidad de Roehampton (Reino Unido) del 1 de junio al 31 de agosto de 2012.
} 
transformación de esta configuración, apuntaremos vías de intervención basadas en la innovación representacional.

Palabras clave: violencia de género; representación; medios; política

\begin{abstract}
This paper aims at revising recent debates in Spain on how gender violence has been made visible by placing them within the context of the analysis of, on the one hand, the variables that sustain how the problem has been discursively configured and, on the other, the theoretical and political implications that result from it. Our hypothesis is that the mode of visibilisation, particularly with respect to the use of judicialisation as mediatising strategy, not only deactivates the possibilities to transform the problem but it also reproduces frames of recognition that place women in positions devoid of agency. Since the solution to their ordeal is construed on the basis of filing a complaint, this, in turn, makes them subject to judicial power and control. In order to transform the problem, modes of intervention through representational innovation will be proposed.
\end{abstract}

Keywords: gender violence; representation; media; politics

\title{
INTRODUCCIÓN
}

El presente trabajo tiene como objetivo situar discusiones académicas recientes sobre la visibilización mediática de la violencia de género en España, atendiendo a presentarlas en relación a los principales ejes discursivos e implicaciones teórico-políticas que, en nuestra opinión, se derivan de dicha visibilización. Nuestra hipótesis es que la forma en que se ha visibilizado en los últimos años esa violencia, en particular respecto de la judicialización como estrategia mediatizadora, no solo desactiva las posibilidades de transformarla sino que conforma un marco de reconocimiento donde las mujeres no son sujeto agente. Más bien, su lugar, en tanto que ha sido primordialmente construido desde su papel como víctimas denunciantes, está supeditado al saber y control judicial. Las implicaciones sobre la relación con el poder que ello conlleva serán abordadas progresivamente.

Nuestra aportación se sitúa, pues, dentro de la tradición del paradigma crítico del estudio de medios (según la clasificación de McQuail, 1987), el cual profundiza en el ámbito de la representación como cruce entre el sujeto y la realidad. Desde esta perspectiva, se caracteriza a los medios de comunicación como configuradores de la realidad social, señalando los productos mediáticos de masas como legitimadores del panorama social, político y económico establecido (Brea, 2005; Mattelart, 1994; Mirzoeff, 1999). En concreto, nuestro abordaje analítico profundiza en el carácter político de las representaciones, entendiendo lo político en su despliegue a través de las relaciones estructura- 
les de reconocimiento o desprecio que generan los marcos de inteligibilidad de las gramáticas culturales (Butler, 2009). En particular, nos interesa focalizar sobre las variables en las que se asientan los discursos mediáticos (y políticos) que han conformado la actual configuración de la violencia de género y qué es lo que ponen en juego para una construcción del sujeto femenino en democracia. En este contexto, la tradición epistemológica desarrollada por la teoría crítica feminista de los medios nos permitirá adentrarnos en los patrones de subjetividad y construcción identitaria de lo femenino que los relatos mediáticos enarbolan como marcos de inteligibilidad (De Lauretis, 1984; Halberstam, 2001; Haraway, 1991; Preciado, 2002; Sontag, 2003; Spivak, 1988). Somos conscientes que la propuesta que aquí planteamos responde a un ejercicio de lectura sintomática, contingente y parcial pero, como apunta Haraway: "la única manera de encontrar una visión más amplia es estar en algún sitio en particular" (Haraway, 1991: 339).

Nos mueve, por otro lado, una coyuntura muy particular en el estado español: a raíz de la reforma de los planes de estudio universitarios (siguiendo las directrices del nuevo Espacio Europeo de Educación Superior) se han producido cambios que han propiciado la entrada de nuevas asignaturas y contenidos curriculares para la formación de los/as futuros/as comunicadores/as. Según constata un estudio realizado sobre la Universitat Jaume I de Castellón (VV.AA., 2010) $)^{2}$, aunque son escasos los grados que, por ejemplo en dicha universidad, integran la perspectiva de género o las enseñanzas en materia de igualdad, son las titulaciones de Ciencias de la Comunicación las que cumplen con la normativa en materia de igualdad ${ }^{3}$, a través de la inclusión de una la asignatura obligatoria: Comunicación para la Igualdad.

Es el momento, entonces, de debatir de qué forma las aportaciones de la teoría crítica feminista de los medios, con respecto a la configuración de la violencia de género, pueden ayudarnos a repensar los debates sobre la responsabilidad de los medios y sobre los modos en que los/as comunicadores/as organi-

\footnotetext{
${ }^{2}$ El estudio realizado sobre la Universitat Jaume I, en el que participamos, es el único que conocemos sobre el tema. No tenemos constancia de que existan estudios similares sobre otras universidades españolas. No obstante, nos atrevemos a utilizar los datos obtenidos como sintomáticos. Aunque, por otro lado, podríamos paradójicamente considerar que los resultados son muy optimistas y que el cumplimiento de la normativa en materia de igualdad en los grados de Ciencias de la Comunicación de la Universitat Jaume I se debe, en parte, a la sensibilización y larga trayectoria de dicha universidad en estudios de género y feministas y, por tanto, no ha de ser necesariamente extrapolable a otros contextos universitarios.

${ }^{3}$ La Ley Orgánica 3 / 2007 para la igualdad efectiva de hombres y mujeres aprobada en España establece la necesaria inclusión de las enseñanzas en materia de género en todos los niveles educativos.
} 
zan las informaciones (Bengoechea, coord., 2010; López Díez, 2005). En este sentido, contribuimos a dos de las principales líneas de discusión que se desarrollan en el ámbito de la investigación en comunicación en España: por un lado, el estudio de los contenidos mediáticos (objeto del 53,2\% de las contribuciones científicas según Martínez Nicolás y Saperas Lapiedra, 2011) y, por otro, la responsabilidad social de los medios (segunda temática más desarrollada en las investigaciones, según Castillo y Carretón, 2010).

En definitiva, nuestro objetivo es realizar un análisis crítico del lugar del sujeto político que configuran políticas y discursos sobre violencia de género en España. Asumimos una metodología que hunde sus raíces en el paradigma de la teoría crítica feminista de los medios para probar la hipótesis de que el marco de reconocimiento establecido configura un sujeto 'mujer' desprovisto de agencia. Las conclusiones a las que lleguemos nos permitirán establecer modos de renovación no solo representacional sino docente y teórico-política.

Para llevar a cabo nuestra labor, este trabajo se estructura en tres apartados:

- discusión sobre las principales líneas de debate del estado de la cuestión en España e ilustración con ejemplos sintomáticos actuales;

- crítica teórica de los tres ejes que, en nuestra opinión, sostienen, el marco de reconocimiento establecido por prácticas y discursos y cuestionamiento del sujeto político que conforman;

- propuesta de estrategias que contribuyan a su renovación y reformulación.

\section{EL ESTADO DE LA CUESTIÓN}

La literatura consultada sobre la cobertura informativa dada a la violencia de género en España coincide en señalar que los medios han contribuido indudablemente a la visibilización del problema y se han comprometido en la denuncia y la sensibilización. Ahora bien, dicha contribución no hubiera sido posible sin el trabajo continuado del movimiento feminista en España, el cual, a través del activismo social, la participación política y el debate científico sobre género y comunicación en las universidades ha ejercido un papel primordial en la inclusión del tema en la agenda mediática y política desde la instauración de la democracia en 1975.

En efecto, desde la llegada de la democracia se comenzaron a producir dentro de la academia española trabajos sobre los estereotipos de género en el lenguaje audiovisual (especialmente en la publicidad aunque también en otros corpus), sobre el sexismo en el lenguaje y sobre la construcción audiovisual de la subjetividad femenina. Sin ánimo de ser exhaustivos, puesto que no es 
el objetivo de este trabajo, podemos destacar cronológicamente, por representativos, García Meseguer (1977), Imbert (1982), Fagoaga y Secanella (1986), Colaizzi (1990), Gallego (1990), Peñamarín y Frabetti (1990), Fagoaga (1994 y 1999), Peñamarín y López Díez (coord.), (1995), Martín Serrano y Martín Serrano (coords.) (1995), Bach, Altés, Gallego, Plujá y Puig (2000) y López Díez (2001). Algunos de estos trabajos ya incluyen entre sus líneas de reflexión consideraciones sobre la violencia inscrita a través del sexismo representacional pero no se vinculan con el debate socio-político, creado a raíz de la implicación por parte de las instituciones y los agentes productivos, el cual se inicia, como veremos posteriormente, a finales de los noventa.

A esta producción han ayudado indudablemente los diferentes Planes de Igualdad de Oportunidades y Planes Nacionales y Autonómicos de Investigación que, entre sus líneas de financiación, han incluido el abordaje de cuestiones relacionadas con el género y la comunicación. En este sentido, el último Plan de Igualdad de Oportunidades (2008-2011; elaborado bajo el gobierno socialista $)^{4}$ continúa incluyendo, como uno de sus principales ejes de actuación, la imagen no sexista de las mujeres en la publicidad y establece, como parte del eje sobre violencia de género, líneas de actuación en el campo de la formación, la sensibilización y la prevención.

Las discusiones en estudios de mujeres y medios en España han articulado estos debates sobre estereotipos y lenguaje respecto de sus alcances normativos en dos sentidos: por una parte, desde los años setenta, se ha venido demandando, con mayor o menor debate crítico ${ }^{5}$, una mayor representación de las mujeres en las redacciones. Por otro lado, se han propiciado, a pesar de reticencias y dificultades corporativas (Montiel Roig, 2009; Quílez, 2004), diversas iniciativas por parte del sector. Nos referimos a la elaboración y/o aplicación de manuales y libros de estilo sobre publicidad no sexista y/o tratamiento no sexista de la información (auspiciados por el Instituto de la Mujer) y, también, a la implementación de sistemas y códigos de autorregulación surgidos, desde la segunda mitad de los noventa, a tenor de la creación de organismos como Autocontrol (la Asociación para la Autorregulación de la Comunicación Comercial) o los diferentes consejos audiovisuales autonómicos.

${ }^{4}$ La llegada al gobierno del Partido Popular en noviembre de 2011 y la política de reducción del presupuesto dedicado a educación, investigación y servicios sociales augura un cambio drástico (léase negativo) en este ámbito.

${ }^{5}$ Dicha demanda es objeto de críticas desde posiciones que argumentan que la mera inclusión de mujeres no garantiza un cambio en el modo de mirar. Más bien, sería necesario la formación con perspectiva de género para cualquier profesional. 
Este panorama de producciones científicas, imbricaciones con agentes productivos y labor institucional con respecto al género y la comunicación nos proporciona el sustrato para entender el posterior desarrollo académico e interés social dedicado en exclusiva al tema de la representación de la violencia de género. Dicho interés comenzó a gestarse al saltar a la agenda de los medios en España el escándalo que causó en 1997 el caso de Ana Orantes (asesinada por su exmarido después de que ella contara sus malos tratos en televisión), como han puesto de manifiesto Fagoaga (1999), Berganza Conde (2003), Aran Ramspott y Medina Bravo (2006), Fernández Díaz (2003) y López Díez (dir.) (2006). Hasta ese momento los malos tratos no habían recibido atención mediática más allá de su emplazamiento en la crónica de sucesos. Los estudios sostienen que, a consecuencia del caso Orantes, hubo un cambio sustancial en su abordaje por parte de la prensa: "El suceso provocó la creación de un nuevo enfoque informativo, un nuevo marco de referencia en la narración de episodios de violencia doméstica: estos pasaron de ser tratados como acontecimientos casuales y de sucesos, a ser explicados como un problema social [...] hoy ya constituye un tema de debate en la vida pública" (Berganza Conde, 2003: 9-10).

Trabajos como el de Berganza Conde (2003) y Aran Ramspott y Medina Bravo (2006) inciden, de hecho, en el potencial transformador de dicho cambio. Berganza subraya los beneficios sociales que supuestamente conlleva este nuevo enfoque informativo y Aran y Medina lo examinan bajo el optimismo generado por el momento histórico en el que se sitúa su investigación (alrededor del debate y aprobación en España de la Ley Integral contra la Violencia de Género de 2004): "Pareciera que los medios, y la prensa en concreto, hayan asumido su función como instrumento para educar y concienciar a la sociedad" (Aran Ramspott y Medina Bravo, 2006: 19).

Sin embargo, a pesar de que la cobertura informativa del problema ha supuesto su visibilización, desde la perspectiva actual, el tratamiento recibido dista mucho de haber supuesto una "reconstrucción subjetiva de la realidad" (Berganza Conde, 2003: 10), como veremos más adelante. Quizá en el momento de la realización de la literatura consultada (en el ambiente social previo y posterior a la Ley de Violencia de Género de 2004 o a la Ley de Igualdad de 2007) sí que se pudieron dar las condiciones para esperar un compromiso real de los medios y un impacto transformador en la opinión pública. Quizá en ese momento sí que se podía colegir que la visibilización mediática comportaría el reconocimiento de que el problema es de índole social (y todos y todas somos responsables) y de que constituía una "violación de los derechos humanos" (Aran Ramspott y Medina Bravo, 2006: 13). 
No nos cabe duda que tanto el caso de Ana Orantes como los meses anteriores y posteriores a la aprobación de la Ley de 2004 colocaron el tema de los malos tratos en primera línea de las agendas informativas y políticas, ambas plagadas de buenas intenciones. De hecho, por parte de las instituciones el foco se puso (y se sigue poniendo) sobre los aspectos asistenciales, sanitarios y jurídicos; por parte de los medios, el debate se centró en denunciar y sensibilizar a la opinión pública, y la academia abundaba en la responsabilidad de aquellos por ofrecer relatos e imágenes no sexistas que contribuyeran a sensibilizar y a educar a la opinión pública en aras de una verdadera transformación del problema.

Las estadísticas sobre víctimas mortales de la violencia de género en España no ayudan, empero, a concluir que dicho problema haya sufrido una importante transformación. Observemos, en primer lugar, la Gráfica 1, elaborada según los datos proporcionados por el Instituto de la Mujer (dependiente del Ministerio de Sanidad, Servicios Sociales e Igualdad) ${ }^{6}$. En ella aparece la evolución en la tasa de asesinatos de mujeres por violencia de género, la cual se ha mantenido estable a pesar de variaciones circunstanciales ${ }^{7}$.

Gráfica 1: Tasa de mujeres asesinadas por violencia de género a manos de su pareja o expareja

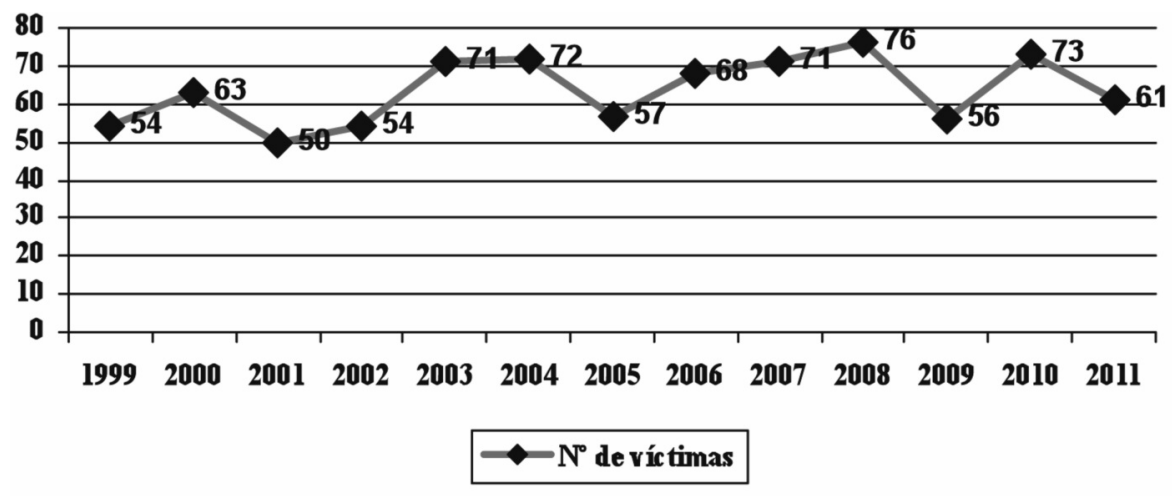

Fuente: Instituto de la Mujer, España

${ }^{6}$ Datos obtenidos de: http://www.inmujer.gob.es/ss/Satellite?c=Page\&cid=1264005678228 \&language=ga_ES\&pagename=InstitutoMujer\%2FPage\%2FIMUJ_Estadisticas

${ }^{7}$ Dichas variaciones en forma de descenso en 2005 y 2009 son atribuibles a:

a) aplicación de los planes desarrollados en 2005 a raíz de la Ley Integral contra la Violencia de Género (aprobada en 2004)

b) aplicación del Plan de Prevención y Atención de la Violencia de Género en Población Extranjera Inmigrante desarrollado en 2009, el cual comporta una caída en el número de mujeres de origen extranjero asesinadas. 
Veamos ahora los resultados respecto al impacto en la sensibilización de la opinión pública. Para ello nos detenemos en los datos que han sido recogidos en sucesivos barómetros del Centro Superior de Investigaciones Sociológicas (CIS) en España. El indicador 'la violencia contra la mujer' empieza a ser contabilizado en el apartado de 'Problemas principales que existen actualmente en España' a partir de septiembre del año 2000. Su evolución hasta 2010 la podemos apreciar en las gráficas 2 y $3^{8}$ :

Gráfica 2: Porcentaje anual de personas que consideran la violencia de género unos de los principales problemas

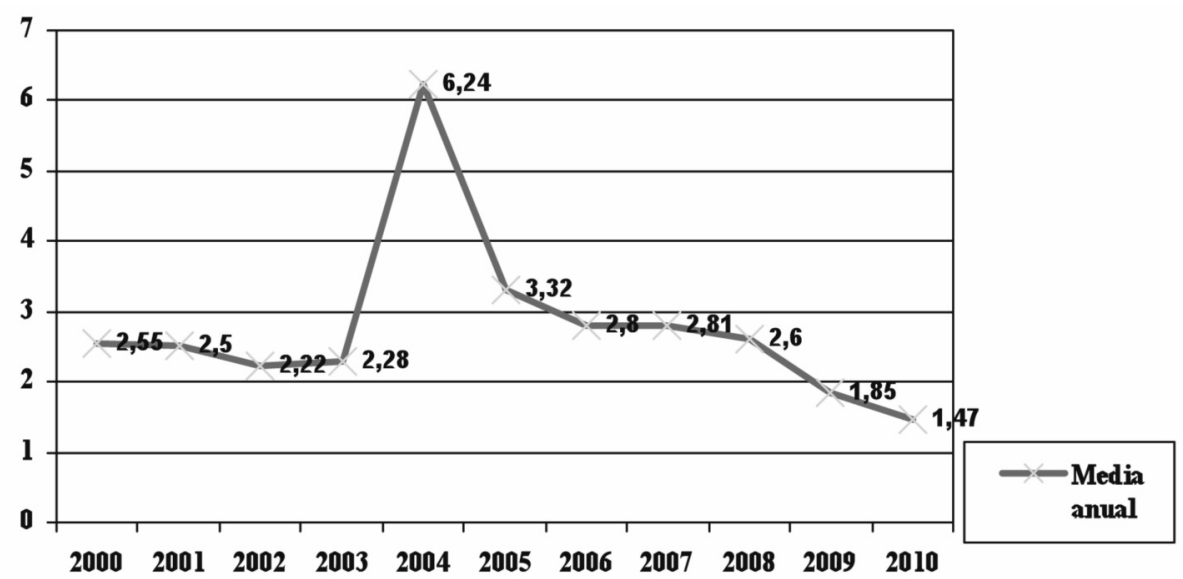

Fuente: Barómetro del CIS 2000-2010, España

Como podemos observar en la Gráfica 2 el mayor resultado se alcanza en el año 2004 (con un 6.24\%), que coincide con la aprobación de la Ley Integral contra la Violencia de Género. A partir de ese momento (sorprendentemente, o no tanto, como veremos más adelante) la línea de evolución va decreciendo, excepto, como se puede apreciar en detalle en la Gráfica 3, en el período comprendido entre el último trimestre de 2006 y el primer trimestre de 2008, cuando sufre

${ }^{8}$ Hemos realizado las gráficas en base a los datos obtenidos de la página oficial del CIS. Dichas gráficas muestran el porcentaje (de 0 a 8 por ciento) de personas que consideran la violencia de género como uno de los principales problemas que existen en España. Nos gustaría realizar algunas aclaraciones a efectos de su lectura: los datos de 2000 corresponden a los meses de septiembre a diciembre; no hay datos anteriores. Los datos del cuarto trimestre de 2001 no incluyen octubre ya que no aparece en la página del CIS. Por otro lado, los datos del tercer trimestre de cada año (en el caso de la gráfica por trimestres) se contabilizan por las encuestas realizadas en junio y julio, en agosto el CIS no encuesta. 
Gráfica 3: Porcentaje trimestral de personas que consideran la violencia de género uno de los principales problemas

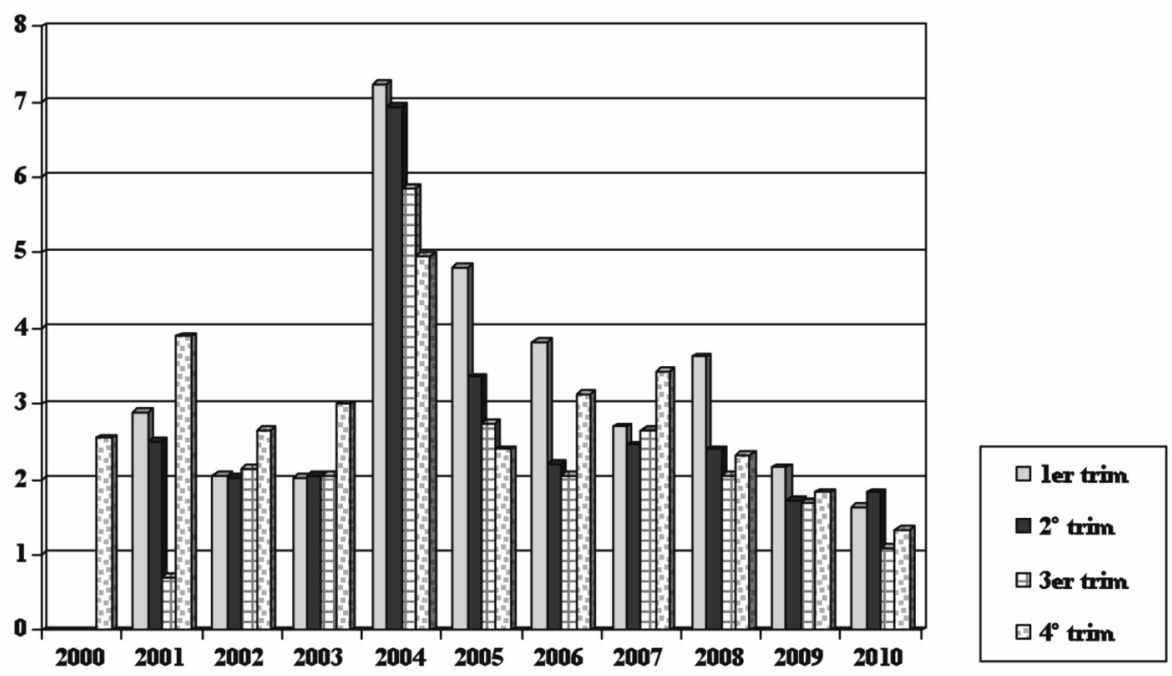

Fuente: Barómetro del CIS 2000-2010, España

una desaceleración en su caída. Dicho período coincide con la etapa de discusión y aprobación de la Ley de Igualdad.

Luego, a pesar de que el problema de la violencia machista contra las mujeres ha sido reconocido y visibilizado, los medios se hacen eco de ello y se han aprobado leyes contra la violencia y por la igualdad, parece que algo falla. La gráfica muestra que la sensibilización social contra la violencia de género, en lugar de aumentar, disminuye progresivamente. El papel de los medios en este contexto es clave ya que, como demuestran los últimos datos de 2011 obtenidos por el Ministerio de Sanidad, Servicios Sociales e Igualdad en la encuesta sobre la percepción social de la violencia de género, el $87,7 \%$ de los/as entrevistados/as responden que su conocimiento sobre dicho tema procede de los medios ${ }^{9}$.

No es de extrañar, además, como indica Lorente Acosta (2008), que, coincidiendo con el descenso de la sensibilización, por un lado, en 2007 bajaran los porcentajes de suicidios y entrega voluntaria por parte del agresor de un homicidio y, por otro, la mitad de los homicidios se cometan dentro de los tres días

${ }^{9}$ Datos obtenidos del IV Informe Anual del Observatorio Estatal de Violencia sobre la Mujer, accesible en: http://www.uca.es/recursos/doc/unidad_igualdad/1693412868_11220 11112649.pdf, p. 16. 
posteriores a uno previo. Brändle, Cárdaba y Ruiz (2011) previenen en este sentido a la profesión y le piden eficacia en sus acciones comunicativas contra la violencia ante el riesgo de aparición del efecto boomerang por dichas acciones.

Por otro lado, esa disminución de sensibilización social corre paralela a lo que se ha denominado un "rearme del machismo"10. Este rearme se sostiene sobre la idea de que la Ley contra la Violencia de Género es discriminatoria contra los hombres (ya que supuestamente hay el mismo número de asesinatos por ambas partes), el mito de las denuncias falsas y el supuesto "hembrismo"11 de la Ley de Igualdad.

Llegados/as a este punto nos gustaría traer a colación a Magallón (2006) cuando afirma que "existimos cuando los demás nos dan un lugar". Nadie pone en duda que los medios (y la ley) han dado un lugar a las mujeres víctimas de la violencia de género pero quizá el problema estribe precisamente en el lugar otorgado: la visibilización del problema y los debates suscitados a su alrededor parecen haber encontrado serias dificultades para transformar las prácticas y marcos que sustentan la violencia. Más bien, el reconocimiento construido a través de los relatos mediáticos reproduce, y apoya, esos marcos a través de configuraciones que articulan un sujeto femenino exento de agencia y cuyos mecanismos examinaremos progresivamente.

\section{LA CONFIGURACIÓN DE LA VIOLENCIA DE GÉNERO}

Independientemente de los avances conseguidos en materia de políticas públicas, los estudios sobre violencia de género y medios en España coinciden en señalar que el enfoque adoptado capitaliza sobre el drama de la violencia y los aspectos más trágicos y particulares (Bosch-Fiol y Ferrer-Pérez, 2012; Fernández Romero, 2008; López Díez, 2008; Loscertales, Fernández e Higazi, 2009; Marín, Armentia y Caminos, 2011; Menéndez Menéndez, 2010). Numerosos manuales han salido al paso de esta situación con recomendaciones para un

\footnotetext{
${ }^{10}$ Un reciente reportaje de El País del 8 de abril de 2011 incidía en esta cuestión al titular "¿Violencia de qué?" un texto escrito en respuesta al artículo de El Mundo "Un chico normal", donde el autor, Salvador Sostres, adoptaba una actitud comprensiva ante el asesino de una joven, el cual, tras cometer el crimen, mostró su cadáver a través una webcam. Sostres no solo mencionaba la violencia psicológica que supuestamente había sufrido el asesino al saber que su novia, embarazada de un niño que no sabía si era suyo, iba a dejarle sino que, por otro lado, justificaba el asesinato sobre la base de un amor incontrolado. En el artículo de El País, por el contrario, las autoras, Charo Nogueira y María R. Sahuquillo, denunciaban que la publicación de Sostres era un ejemplo de los discursos que minimizan la violencia machista y ponía de manifiesto cómo "las medidas en pro de la igualdad real entre mujeres y hombres han generado un rearme del machismo [...]" (Nogueira y Sahuquillo, 2011).

${ }^{11} \mathrm{Al}$ contrario que "machismo", dicho término carece de toda base epistemológica.
} 
adecuado tratamiento informativo de la cuestión; entre ellos destacamos Fernández Arribas y Noblejas (eds.) (2010) y López Díez (dir.) (2006). Sin embargo, la cobertura que nos seguimos encontrando configura un lugar para las mujeres que desactiva su capacidad de agencia.

El tratamiento mediático que la violencia de género ha tenido en España a través de campañas, programas de televisión, noticias en prensa y televisión, películas etc. es, obviamente, ingente pero, en aras de ilustrar nuestro argumento, mencionamos seguidamente algunos casos actuales por sintomáticos y/o representativos.

En los últimos meses podemos encontrar titulares de prensa como los diez que incluimos a continuación (detallamos también los subtítulos en algunos (asos) $)^{12}$ :

1. El País 02/05/2012 (edición digital): Un hombre de 58 años mata a puñaladas a su pareja de 25 en Elche. El supuesto agresor llamó después a la Policía Nacional para entregarse ${ }^{13}$.

2. El País 22/06/2012 (edición digital): La marca de la posesión machista. Miles de mujeres son atacadas cada año con sustancias corrosivas. Los agresores intentan condenarlas al ostracismo social ${ }^{14}$.

3. El País 09/07/2012 (edición digital): Un hombre mata a su hijo y se estrella con él en su coche a la vista de su mujer. "Asómate a la ventana para ver lo que te mereces", le dijo a su esposa por teléfono. El cuerpo del menor presenta varias heridas por arma blanca ${ }^{15}$.

4. El Mundo 24/04/2012 (edición digital): Fin de semana trágico por la violencia machista: una muerta y cuatro heridas ${ }^{16}$.

5. El Mundo 25/06/2012 (edición digital): La mujer asesinada en Galicia denunció varias veces a su ex novio por maltrato ${ }^{17}$.

6. ABC 24/06/2012: Una mujer asesinada y cuatro heridas por sus parejas en apenas 24 horas. Un hombre se ha suicidado hoy en Alicante tras agredir a su pareja con una escopeta. Ayer, una mujer era asesinada en Gijón y otra herida de gravedad en Tenerife. En ninguno de los tres casos había denuncias previas $^{18}$.

${ }^{12}$ Adjuntamos ejemplos de cabeceras tanto de tirada nacional (El País, El Mundo y ABC) como regional (Diario de Sevilla y Diario Vasco) así como de la web de Radio Televisión Española (RTVE).

${ }^{13} \mathrm{http} / / /$ ccaa.elpais.com/ccaa/2012/05/02/valencia/1335944427_282579.html

${ }^{14}$ http://sociedad.elpais.com/sociedad/2012/06/22/actualidad/1340390169_472566.html

${ }^{15} \mathrm{http} / / /$ sociedad.elpais.com/sociedad/2012/07/09/actualidad/1341848190_297514.html

${ }^{16} \mathrm{http} / / /$ www.elmundo.es/elmundo/2012/06/24/espana/1340531850.html

${ }^{17} \mathrm{http} / / / w w w . e l m u n d o . e s /$ elmundo/2012/06/25/espana/1340652170.html

$18 \mathrm{http}: / / \mathrm{www} . a b c . e s / 20120624 /$ espana/abci-violencia-genero-alicante-2012062411 08.html 
7. Diario Vasco 26/03/2012 (edición digital): La mujer asesinada en Tolosa no había presentado denuncia por malos tratos. La pareja de la víctima, un joven de 26 años, ha confesado ser el autor del crimen. La mujer fue hallada muerta en su domicilio con signos de violencia ${ }^{19}$.

8. Diario de Sevilla 16/04/2012 (edición digital): La mujer asesinada por su marido pensaba separarse esta semana. El esposo se lanzó desde la azotea del bloque de pisos donde vivían minutos después de que el hijo descubriera el cadáver de la madre. Es la primera víctima por violencia de género en Sevilla este año ${ }^{20}$.

9. RTVE 30/01/2012 (página web): La violencia de género se cobra la vida de dos mujeres en Jaén y Ciudad Real. En Campo de Criptana una mujer de 43 ha sido hallada en su domicilio. En Villacarrillo el presunto asesino de su expareja se encuentra detenido ${ }^{21}$.

10. RTVE 12/05/2012 (página web): Hallada muerta una mujer y su marido ahorcado en Manzanares (Ciudad Real). El matrimonio estaba en trámite de separación. La Guardia Civil investiga el suceso. El 016 es el número de atención a las víctimas de violencia de género ${ }^{22}$.

La imagen que conforman estos titulares es la de un constante goteo de mujeres (ejemplos 4, 6 y 9) víctimas de una violencia relatada melodramáticamente (ejemplos 1, 2 y 3; "puñaladas", "posesión", "Asómate a la ventana para ver lo que te mereces") contra la que ni las denuncias ni los intentos de separación funcionan (ejemplos 5, 8 y 10). Su identidad, además, se define por estar muertas, heridas o asesinadas. En ocasiones parece ni siquiera que la violencia tenga un ejecutor concreto (ejemplo 9). Aunque, cuando la noticia focaliza sobre la detención del agresor (como ocurre con noticias relacionadas que podemos encontrar en la página del ejemplo 9) ${ }^{23}$, la redacción busca siempre la causa de la agresión (discusiones, separación, celos...), y, en el peor de los casos, sirve para asignar parte de la responsabilidad a la mujer por su estilo

${ }^{19} \mathrm{http} / / /$ www.diariovasco.com/20120326/local/detenido-hombre-tolosa-tras-2012032 60803.html

${ }^{20} \mathrm{http}: / /$ www.diariodesevilla.es/article/sevilla/1233844/hombre/mata/su/esposa/y/despues/se/suicida/desde/una/azotea.html

21 http://www.rtve.es/noticias/20110130/muere-una-mujer-anos-campo-criptanasupuestamente-tras-ser-acuchillada-por-marido/399672.shtml

22 http://www.rtve.es/noticias/20120512/hallada-muerta-mujer-su-marido-ahorcadomanzanares-ciudad-real/525178.shtml

${ }^{23}$ Detenido un hombre en Jaén como presunto autor de la muerte de su expareja. El presunto autor de la muerte de la mujer en Cartagena es detenido por la Guardia Civil. Detenido un hombre que ha confesado haber estrangulado a su mujer en Fuenlabrada. Ejemplos accesibles en: http://www.rtve.es/noticias/20110130/muere-una-mujer-anos-campocriptana-supuestamente-tras-ser-acuchillada-por-marido/399672.shtml 
de vida ${ }^{24}$, acciones u omisiones (ejemplo 7). Esta característica (aunque no es la única) se da tanto en prensa escrita como en los informativos de televisión (López Díez, dir., 2006; Loscertales et al., 2009), a pesar de que todos los manuales previenen sobre esta práctica y, en el último informe de 2011 del Observatorio Estatal de Violencia sobre la Mujer, entre un 35\% y un $40 \%$ de la población consultada opina que las noticias presentan a la víctimas como responsables de la agresión ${ }^{25}$.

Este último mecanismo de responsabilización de la víctima puedes ser rastreado, por otro lado, en los programas de corazón españoles que especialmente entre 2003 y 2006 entrevistaban a famosas mujeres maltratadas con grandes éxitos de audiencia (Gámez Fuentes, 2009). Las invitadas tenían que contestar preguntas de los/as periodistas que denotaban la ausencia de conocimiento sobre las complejidades del tema ("¿Por qué aguantaste nueve años y medio de malos tratos?", "¿Esos insultos y malos tratos te los aplicó con y sin sustancias (drogas)?"); se cuestionaba la veracidad del testimonio de violencia especialmente si la mujer era vedette o no presentaba una actitud victimista; se la estigmatizaba si, posteriormente al maltrato, cobraba por aparecer en portadas de revistas hablando sobre el tema (desviando la atención del tema de la agresión) y se la responsabilizaba si sus hijos habían sufrido las consecuencias del maltrato ("¿Hay un hombre violento y un niño de cuatro años que os ve y te anuló de tal manera que no podías apartar a tu hijo de él?").

Las imágenes procedentes de iniciativas de carácter sensibilizador no abundan desgraciadamente en aspectos que configuren un imaginario de las mujeres

${ }^{24}$ Recomendamos en este sentido leer con detalle el texto de la noticia del ejemplo 1. En él se hace alusión a la "presunta dedicación a la prostitución" de la mujer asesinada, a sus "presuntos problemas de drogadicción", a los "múltiples antecedentes policiales de la víctima" y a "la posibilidad de que la fallecida tuviera otra u otras relaciones sentimentales". En el mismo artículo se menciona la "ausencia de antecedentes del agresor". Este caso levantó una gran polémica en la red como puede apreciarse en: blogs.elpais.com/defensor-dellector/2012/05/violencia-machista.html.

${ }^{25}$ Datos obtenidos del IV Informe Anual del Observatorio Estatal de Violencia sobre la Mujer, accesible en: http://www.uca.es/recursos/doc/unidad_igualdad/1693412868_1122011 112649.pdf, p. 17. Por otro lado, recientes estudios sobre la respuesta de las audiencias ante imágenes de violencia contra las mujeres y su relación con la aceptación de estereotipos sexistas, corroboran que la forma en que un producto audiovisual presenta la violencia de género afecta los estereotipos de la audiencia en cuanto al género, la aprobación (o no) de la objetivización de la mujer y la asunción (o no) de mitos sexistas relacionados con la violación (Capella, Hill, Rapp y Kees, 2010; Fernández-Villanueva, Revilla-Castro, Domínguez-Bilbao, Gimeno-Jiménez y Almagro, 2009; Lee, Hust, Zhang y Zhang, 2011). Desde el área de la psicología social podemos encontrar también estudios que demuestran la relación entre creencias sexistas y legitimación de la violencia contra las mujeres (Herrera Enríquez y Expósito, 2009; Valor-Segura, Expósito y Moya, 2011) 
maltratadas mucho más empoderador que el descrito hasta ahora, como apunta Fernández Romero (2008). En concreto, las diferentes campañas de sensibilización institucionales elaboradas desde 1998 (cuando surge el I Plan de Acción contra la Violencia Doméstica) se dirigen a las mujeres y la sociedad incidiendo en que las mujeres han de denunciar y que la sociedad es responsable de acabar con esa lacra social con mensajes como "Denunciemos los malos tratos. Siempre se puede volver a empezar", "La violencia contras las mujeres nos duele a todos, nos duele a todas", "Contra los malos tratos, gana la Ley", "Saca tarjeta roja al maltratador", "No te saltes las señales. Elige vivir". Sin embargo, en este ámbito, como Fernández Romero (2008) señala, se utilizan imágenes que siguen perpetuando a las mujeres en posiciones de víctima (mostrando o no las consecuencias físicas de la violencia) y con la responsabilidad de denunciar para que la institución las asista.

En aras de completar una fotografía sintomática lo más diversificada posible de los formatos en los que encontramos diferentes representaciones de la violencia machista en España ${ }^{26}$, nos gustaría traer a colación el reportaje Golpe a golpe, emitido en 2010 por la cadena española Cuatro con motivo del Día Internacional contra la Violencia de Género. Dicho reportaje resulta, además, especialmente interesante en la tarea que nos ocupa dado que aglutina los diferentes aspectos que hasta ahora hemos subrayado.

En la página web de la cadena se anunciaba: "Callejeros se sumerge en el mundo de la violencia de género, de la mano de sus víctimas" ${ }^{27}$. En la nota de prensa se destacaban frases del reportaje como: "Es la tercera vez que me pega, pero hasta ahora no le había denunciado... porque le quiero", "intentó ahogarme", "es la tercera vez que vengo, ¿qué es lo que tiene que hacerme para que me hagan caso... matarme?", "me tenía tan aislada que un día salí a tirar la basura, vi una rata y la sonreí porque era el único ser vivo con el que podía tener una cierta complicidad" o "voy a perdonarle". Por otro lado, la nota explicaba partes del contenido del reportaje con expresiones como: "mujer inglesa visiblemente

\footnotetext{
${ }^{26}$ Somos conscientes de que también existen productos fílmicos que abordan el tema que nos ocupa pero, dados los objetivos de este trabajo, nos interesan solamente aquellos formatos en los que prevalece la información o sensibilización como principal estrategia comunicativa. El abordaje de los productos fílmicos excedería los objetivos de este artículo y su investigación merecería centrarse en cuestiones de tradiciones narrativas que situarían el debate en otro ámbito y en otro estado de la cuestión. Dicho estudio está siendo llevado a cabo en forma de tesis doctoral titulada La violencia de género en el cine español, realizada por Vera Burgos, en proceso de realización en la Universitat Jaume I y codirigida por la autora del presente texto. Por otro lado, para un acercamiento introductorio al tratamiento de la violencia en el cine se puede consultar Gámez Fuentes (2007).

${ }^{27} \mathrm{http}: / /$ www.cuatro.com/callejeros/especiales. Fecha de visita: 09/02/2011.
} 
asustada recibe a la autoridad", "la joven se desmorona ante una pareja de mujeres de la unidad de policía local", "el juez decide no tomar medidas cautelares porque considera que simplemente es un enfrentamiento por la custodia de los hijos y no hay pruebas", "una mujer acude a declarar [...] con su bebé en un carrito [...] carrito que custodian las funcionarias del juzgado mientras ella pasa el mal trago".

Después del visionado podemos constatar que: las mujeres representadas en el reportaje aparecen atemorizadas, en estado de pánico, violadas, golpeadas y traumatizadas; a la hora de denunciar sus testimonios revelan que se encuentran entre la soledad, la vergüenza y la falta de respuesta por parte de la justicia; aunque el programa dice que el problema afecta a mujeres de todos los niveles, los personajes femeninos que aparecen son, mayoritariamente, indigentes, inmigrantes, ilegales y dependientes. Por otro lado, es de reseñar que la reportera, al despedirse de una mujer en situación de indigencia y de otra de origen nigeriano, a las que previamente ha entrevistado y "retratado" en su reportaje, les dedica un "¡Suerte, guapa!" respectivamente (reforzando así la idea de que la violencia depende del destino individual). Por otro lado, somos testigos del testimonio ofrecido por un terapeuta de maltratadores quien apunta a que la causa del maltrato es que los hombres que maltratan no saben gestionar sus emociones (de nuevo, se subraya el carácter subjetivo e individual de un perfil psicológico "disfuncional"), aunque hemos de reconocer que menciona la educación como posible variable causal pero sin desarrollar más allá este planteamiento ni vincularlo a las relaciones de desigualdad social.

El programa finaliza con un montaje de noticias en las que el denominador común es la repetición de la palabra "otra" (para referirse al goteo incesante de nuevas víctimas de la violencia machista) salpicada con expresiones como "la mató y la metió a trocitos en la nevera" y una última imagen de un entierro y campanas a muerte.

Recordemos, de nuevo, que este reportaje se emite en 2010, con motivo del Día de la Violencia de Género y después de que hayan pasado, a nivel nacional, seis años desde la aprobación en 2004 de la Ley Integral contra la Violencia de Género y tres desde la aprobación en 2007 de la Ley de Igualdad y, a nivel internacional, 31 desde la Convención de la Eliminación de todas las formas de Discriminación contra las Mujeres (CEDAW), aprobada en 1979 por la Naciones Unidas, y dieciséis desde la IV Conferencia Mundial de las Mujeres de Beijing, entre cuyos objetivos estratégicos se encuentra prevenir y eliminar la violencia contra las mujeres. Y no olvidemos que, además, 2010 es el año de aprobación de la Ley General de Comunicación Audiovisual que pretende un mayor control de los contenidos en aras de la protección de los intereses sociales y valores constitucionales (Belando Garín y Montiel Roig, coord., 2011). 


\section{LOS LÍMITES DEL RECONOCIMIENTO: UN PROCESO SIN SUJETO AGENTE}

En la línea de lo que hemos discutido hasta ahora, el análisis de Golpe a golpe nos permite focalizar, no por su carácter aislado sino por el marco general de inteligibilidad/interpretación que reproduce, en los límites normativos del reconocimiento que configura: el desempoderamiento, victimización e incapacidad de las mujeres para transformar las propias condiciones de vida. Es preciso resituar estos límites normativos desde su carácter de configuración representacional biopolítica (Preciado, 2002) respecto de los modos de control y disciplinamiento de género, dado que el marco de reconocimiento construido privilegia lugares concretos, y excluyentes, desde donde abordar y, por ende, no abordar, el problema de la violencia contra las mujeres, en particular, y nuestro lugar como sujetos en democracia, en general.

Esos lugares concretos se construyen a través de un proceso de representación que se sostiene, desde nuestra perspectiva, sobre tres ejes: el desinterés por parte de lo medios en contextualizar el tema en el marco internacional de lucha política en el que se origina (la transformación de las condiciones de desigualdad estructurales); el peso del legado de la mirada patriarcal en los relatos mediáticos (priorizando el género narrativo dramático que incide en las víctimas y sus circunstancias particulares) y la constante traducción de las experiencias de violencia en base a las "tecnologías" policiales y judiciales. Veamos las implicaciones que se derivan de cada uno de ellos.

Las agendas de los organismos internacionales llevan desde 1979 (con la aprobación de la Convención para la Eliminación de la Discriminación contra las Mujeres-CEDAW) trabajando por la erradicación de todas las formas de discriminación y violencia contras las mujeres y sitúan el problema, incuestionablemente, como una violación de los derechos humanos. Esto se reitera en el último documento publicado en este sentido, Manual de legislación sobre la violencia contra las mujeres (División para el Adelanto de la Mujer, 2010: iv): uno de los cinco principales objetivos que establece para 2015 es la adopción por parte de todos los países de legislaciones en conformidad con las normas internacionales en derechos humanos. Además, en el capítulo de Prevención (capítulo 3.5.) se señalan las vías de implementación por las que ha de pasar dicha prevención, a saber: incorporación de disposiciones en materia de prevención de la violencia contra la mujer (hace especial mención a los estereotipos en planes de estudios y medios de comunicación); concienciación (a través de campañas); planes de estudios y sensibilización de los medios de comunicación de masas. 
Como hemos visto, en España existen leyes en materia de igualdad y violencia contra la mujer que recogen esos lineamientos marcados por Naciones Unidas. Existen también multitud de campañas de denuncia y concienciación contra la violencia de género, sin embargo, como ya se señaló en otro trabajo (Gámez Fuentes y Blázquez Chaves, 2005) y hemos continuado ejemplificando aquí, el foco es sobre la mujer como víctima, el drama de la violencia y la denuncia como único patrón de subjetivación. A pesar de las buenas intenciones, los medios acaban activando, a través del recurso a testimonios individualizados, modos de subjetivación que tienden a producir noticias, imágenes y relatos que aíslan, fragmentan y limitan, por efecto, los alcances transformadores del proyecto de sensibilización que pretenden.

Esto, por otro lado, nos lleva al segundo eje sobre el que se incardina el proceso de visibilización: la mirada patriarcal en el tratamiento de la violencia contra las mujeres. Son ya diversos los trabajos en los que hemos abordado las graves deficiencias en el tratamiento mediático y fílmico de la violencia contra las mujeres (Gámez Fuentes, 2007 y 2009). El breve panorama esbozado en apartado anteriores nos da una idea de la magnitud del problema, a pesar de todo el camino andado desde 1997. Recordemos, en este sentido, varias cuestiones: se buscan las causas individuales que llevan al maltratador a cometer el delito; se centran casi exclusivamente en el maltrato físico nunca en la violencia cultural; se enfatiza el aspecto trágico del asunto ${ }^{28}$ (tanto en programas e informativos como en campañas de concienciación); se focaliza sobre la víctima y las acciones y/u omisiones que han llevado a tal situación (por ejemplo, retirada de denuncias o incumplimiento de órdenes de alejamiento por parte de la víctima). En definitiva, el mensaje que se transmite es que las mujeres que intentan salirse de las normas establecidas están abocadas a la tragedia, y, por otro lado, esto conlleva la idea que son necesarias medidas de protección para poder vivir esa vida fuera de lo establecido. Se refuerza así la configuración patriarcal de la mujer como víctima que necesita ser "tutelada" por el sistema ${ }^{29}$.

${ }^{28}$ Incluso los trabajos de Berganza Conde (2003) y Aran Ramspott y Medina Bravo (2006), antes citados, que celebraban los beneficios del supuesto cambio de enfoque informativo, se atrevían a apuntar el peligro de caer en el sensacionalismo o la espectacularización del tema debido a su abordaje en términos de tragedia.

${ }^{29} \mathrm{Si}$ consultamos literatura especializada sobre la representación de otras formas de violencia contra la mujer fuera de nuestras fronteras y más allá de los malos tratos los resultados no son más esperanzadores. Andrijasevic (2007), en su estudio sobre campañas de los noventa dirigidas a combatir el tráfico de mujeres en el este y sudeste de Europa y en la antigua Unión Soviética, concluye que: dichas campañas despliegan una fascinación fetichista por la mujer forzada, reproducen estereotipos sobre las mujeres del este como bellas víctimas (desde una erotización voyeurística) y se las confina de vuelta al hogar como única solución, haciendo caso omiso de los factores político-económicos en los que 
La inclusión de la violencia de género en la agenda de los medios no va, pues, paralela a una sensibilización sobre la sociedad machista que subyace a la violencia, como apoyaban Berganza Conde (2003) y Aran Rasmpott y Medina Bravo (2006). Tampoco comporta un cambio en el modo binario (masculinofemenino) que define patriarcalmente los comportamientos inteligibles de mujer víctima frente a hombre agresor (Butler, 1990; De Lauretis, 1989; Halberstam, 2001). De ahí se entiende la indignación social, linchamiento mediático y escándalo producidos en España en 2008 por el caso de Violeta Santander, una mujer que se salió de la matriz de inteligibilidad de lo que constituye ser mujer y víctima de maltrato al no aparecer como víctima ni denunciante, ni humilde, ni agradecida por haber sido "salvada" por Jesús Neira de la supuesta agresión de su novio Antonio Puerta. El problema de la asunción de la agresión sufrida o no por una mujer pasó a segundo plano ante la indignación que provocaba a los/as periodistas/as que Santander no considerara a Neira su héroe, mientras que la Comunicad de Madrid así lo reconoció nombrándolo presidente del Consejo del Observatorio Regional de la Violencia de Género ${ }^{30}$.

Inclusión en la agenda no implica, pues, necesariamente transformación social. Más bien su cobertura (y, en ocasiones, saturación informativa) produce una "opacidad de la realidad social" (Gil Calvo, 2003: 278) que dificulta continuamente la comprensión de que lo que está latente en la violencia es la sexuación social transmitida a través de la familia, la cultura y las instituciones, como ya apuntaba De Lauretis (1989: 241-244). Martínez Guzman (2010: 296) observa, en este sentido, que "[...] la opacidad de la violencia cultural oscurece la comprensión de las situaciones de dominación, sobre todo a quienes estén en situación de dominadores, aunque [...] puede cegar también a dominados y dominadas".

No es casual que dicha opacidad y oscurecimiento coincida con una focalización informativa (y estatal) sobre los aspectos policiales y judiciales (Foucault, 1979 y 1981). Esto nos lleva al tercer eje de nuestro argumento: la repre-

la migración y la prostitución forzada ocurren e, incluso, colapsando ambos fenómenos. En definitiva, se equipara nuevamente lo femenino con la carencia de agencia y la pasividad.

${ }^{30}$ Exceden a los parámetros de este trabajo el análisis del tratamiento de este caso así como la discusión en profundidad de las diferentes aristas que contiene (la negación de Santander a ser considerada una víctima; el ensañamiento por parte de los/as periodistas con ella por su rechazo a catalogar a Neira de héroe y no admitir el maltrato; el estado de coma en el que éste estuvo durante meses no por las lesiones recibidas sino por negligencias médicas en su diagnóstico inicial; los reconocimientos otorgados a Neira después de su recuperación; su nombramiento como presidente del Consejo del Observatorio Regional de la Violencia de Género de la Comunidad de Madrid y su posterior destitución al ser detenido por conducir triplicando la tasa de alcoholemia), pero para un acercamiento inicial se puede consultar Fonseca (2010). 
sentación, y por tanto "traducción" (trasladando la formulación de Spivak, 1988), de la realidad que viven las mujeres víctimas de la violencia se realiza únicamente sobre la base de las "tecnologías" (Foucault, 1980) policiales y judiciales. Esto, obviamente, nutre a la vez que se retroalimenta de la necesidad mediática de relatar lo visible: la violencia es un género fácil de contar y con una gran tradición narrativa (Gámez Fuentes y Blázquez Chaves, 2005), pero deberíamos recordar, como bien dice Benet (2007), que existe un conflicto ético (o, por lo menos, creemos que debería existir entre los y las profesionales) "entre la representación icónica del hecho y la verdad experimentada" (Benet, 2007: 16).

Ya Fagoaga en 1994 señalaba que el trabajo periodístico en el ámbito del delito estaba fuertemente supeditado a las fuentes procedentes de la policía y los juzgados y recomendaba que, puesto que los malos tratos se habían tipificado como delito, era necesaria una gran labor de negociación con dichas instancias para incorporar nuevas prácticas significantes que rompieran con la fuerte esterotipación del lenguaje procedente de ellas (Fagoaga, 1994: 88). Parece que dicha labor de negociación no ha sido realizada o no ha surtido efecto debido a los desajustes entre lo que indica la norma legal y las resistencias por parte de los modos de funcionamiento de empresas de comunicación y de instancias policiales y judiciales (Montiel Roig, 2009).

Es preocupante, por otro lado, que ni siquiera los bien intencionados manuales de tratamiento no sexista de la información o las recomendaciones sobre cómo informar sobre los malos tratos o los libros de estilo de periódicos como Público se escapen de la consideración de los poderes policiales y judiciales como fuentes prioritarias y primordiales en la búsqueda de información ${ }^{31}$. Apreciamos las buenas intenciones de investigar lo que no se ve y consultar a expertos/as, pero normalmente el apartado de "lo que no se ve" se limita a las malas relaciones anteriores de la pareja y, entre los/as expertos/as, jamás se cita a especialistas en género solo especialistas del ámbito judicial o policial (López Díez, dir., 2006).

En estudios previos se han apuntado vías de trabajo en las que se han de embarcar los/as profesionales de medios de comunicación y de la educación para romper con los estereotipos sexistas (Gámez Fuentes, 2009), pero aquí nos interesa profundizar en las implicaciones teórico-políticas de la cuestión.

${ }^{31}$ Cfr. http://www.publico.es/espana/39045/manual-de-la-redaccion. Este manual aparece también como decálogo para informar en la web de Mujeres en red. El periodico feminista, cfr. http://www.nodo50.org/mujeresred/spip.php?article1290. Véanse, por otro lado, las Recomendaciones de la Secretaría de la Comisión de Asuntos Profesionales y Deontológicos de la FAPE (Federación de Asociaciones de Periodistas de España), accesible en: http://www.comisiondequejas.com/Otras_Normas/Recomendaciones/Relacion/Violencia_ genero.pdf. 
Llegados/as a este punto nos gustaría traer a colación un estudio de Schmal y Camps (2008) sobre los discursos de los/las agentes del ámbito judicial en relación a la Ley Integral contra la Violencia de Género en España. Como veremos, sus conclusiones son relevantes porque, aunque proceden de otra área de conocimiento, apoyan nuestros argumentos y destapan los peligros inherentes a basar las informaciones en la traducción judicial del fenómeno de la violencia machista.

El objetivo de Schmal y Camps (2008) era analizar "cómo se construye y asigna significado a la Ley Orgánica 1/2004, de 28 de diciembre de Medidas de Protección Integral contra la Violencia de Género" para intentar "comprender estas significaciones, a partir de los discursos de jueces, abogados/as, fiscales y secretarios/as judiciales que son quienes configuran cotidianamente la realidad judicial' alrededor de la violencia de género" (Schmal y Camps, 2008: 3334). Después de un minucioso análisis de los estereotipos y prejuicios imbuidos en la actuación interpretativa de los diferentes agentes, las conclusiones a las que llegan las autoras son reveladoras:

Destaca en los discursos la constante traducción jurídica de las necesidades de las mujeres. La ley -asumida por los/as agentes jurídicos- regula y fija lo que considera que debe ser la salida a las situaciones de maltrato, identifica y conforma a las partes, interpreta, establece los procedimientos, marca el tiempo y espacios de resolución y desactiva el contenido ideológico y político de la violencia. La incidencia y preeminencia de la ley en todos los aspectos de la vida condiciona el objeto del debate y restan difusas las posibilidades de profundizar en aspectos que permiten dar un giro a la manera en que se han construido las relaciones de desigualdad. La ley se ocupa del problema, regulándolo y codificándolo meticulosamente, haciéndolo girar en torno a la denuncia (Schmal y Camps, 2008: 53). [El énfasis es nuestro]

De lo expuesto se colige que el énfasis dado por los medios, la sociedad y las instituciones al aspecto judicial de la violencia es incongruente con el deseo de transformarla, como coinciden Vives-Cases y La Parra Casado (2008), quienes detectan que, en entrevistas realizadas entre 2002 y 2003 a parlamentarios/as miembros/as de la Comisión para erradicar los malos tratos, se pone de manifiesto ya la creencia que la principal solución para acabar con la violencia de género pasa por la denuncia de las mujeres. Esto supone, a su vez, una dificultad para aproximaciones científicas que no reproduzcan los marcos de reconocimiento establecidos dado que, como apuntan Casado Aparicio y García García (2006), "[...] nuestro sentido común acerca de la violencia de género está comprometido con los principios modernos de libertad y autonomía de un individuo que se postula como sujeto soberano al que además ampara la ley en 
tanto que garante de ese orden moderno", por lo que "[... la mujer es interpelada como víctima cuya liberación pasa por la toma de la palabra [...]" (Casado Aparicio y García García, 2006: 92), es decir, la denuncia.

Adelman (2009) nos recuerda, en este sentido, las serias consecuencias derivadas de la forma en que se enmarca un problema ya que dicho marco determina en gran medida la solución. Luego, si la violencia de género se representa como una situación en la que una mujer es agredida o asesinada, la solución es proteger a la víctima que denuncia y castigar al agresor a través de la implementación de medidas legales o de los servicios sociales. Pero, ¿dónde queda la prevención?, ¿dónde quedan las mujeres que no llegan a denunciar?, ¿es posible la construcción de un sujeto femenino soberano sin denuncia?, ies posible desmontar la responsabilidad individual frente a una responsabilidad colectiva? La mera judicialización del problema no alcanza para su transformación y, desgraciadamente, los medios la están tomando como principal marco de enfoque contribuyendo así a la opacidad de la situación de dominación que sustenta la violencia.

\section{HACIA UNA INTERVENCIÓN TRANSFORMADORA}

Resumiendo: desde los debates sobre medios que hemos recuperado podemos decir que el conocimiento que construyen los medios sobre las mujeres víctimas de la violencia es un conocimiento ajeno a la legislación nacional e internacional (que explícitamente enmarca el fenómeno como un atentado contra los derechos humanos y en un contexto de desigualdad estructural que hay que transformar), construido desde una mirada patriarcal que invisibiliza las raíces del problema y lo "traduce" en términos policiales y judiciales, con lo que el énfasis performativo se sitúa sobre la denuncia y visibilización del síntoma, la violencia visible y, a poder ser, denunciable.

Con nuestro análisis y crítica de la actual configuración mediático-política de la violencia de género no pretendemos restar importancia a los logros legislativos conseguidos ni a los esfuerzos mediáticos por visibilizar el problema. Sin duda necesitamos un sistema punitivo contra la violencia pero, una vez que la responsabilidad legal se atribuye, nos preguntamos, inspirados/as por Butler (2008), si la responsabilidad completa se ha asumido por todos/as los/as agentes implicados/as. La facilidad con la que se ha asimilado el sexismo con la violencia (sin una adecuada profundización en los debates de la teoría feminista sobre las relaciones de poder), unido al excesivo papel social del derecho penal en su abordaje, han acabado diluyendo las reivindicaciones de los movimientos feministas (De Miguel Álvarez, 2003; Osborne, 2008). La mera normativización no produce cambio. 
Ante este panorama, y dentro del ámbito del trabajo de los medios, se plantea la necesidad de buscar vías de acción de transformación real y radical de la desigualdad cultural que alimenta la violencia. López Díez (2004) apunta, en este sentido, que una vía para abordar el problema presentado a la teoría feminista de la comunicación en el debate sobre violencia, mujeres y medios sería introducir una perspectiva que vinculara la subjetividad individual de la mujer con las experiencias de las mujeres como colectivo y con el sujeto del feminismo. Ahora bien, hemos de tener en cuenta en todo momento los peligros de institucionalización del debate sobre género y comunicación en la política y en la universidad ya que, a pesar de la proliferación de estudios, proyectos y publicaciones, el problema de la visibilización de la violencia de género que aquí hemos discutido pone sobre la mesa los desafíos en la erradicación de la desigualdad. La institucionalización ha conllevado una pérdida del componente crítico originario y se necesita un replanteamiento teórico para "situar los estudios sobre comunicación y género en el marco en el que nacieron y cobran sentido, el marco de la teoría feminista" (Burkle y Reigada, 2006: 12), además de posibilitar que esta reformulación permee los contenidos universitarios.

En nuestra opinión, este proyecto pasa por mantener activo el "contenido ideológico y político de la violencia" (Schaml y Camps, 2008: 53) y superar la interpelación constitutiva de subjetividad construida sobre la denuncia. El proyecto no es menor y demanda creatividad. Quizá podríamos apuntar que, si efectivamente la violencia cultural que nos constituye como sujetos lo hace sobre una matriz de sexuación social que implica en su misma constitución los conflictos y peligros resultantes de la inteligibilidad, entonces la cuestión reside en construir representacionalmente vías de ocupación del conflicto que lo desvelen y que luchen contra la reproducción iterativa y constitutiva de la violencia:

We are at least partially formed through violence. We are given genders or social categories, against our will, and these categories confer intelligibility or recognizability, which means that they also communicate what the social risks of unintelligibility or partial intelligibility might be $[\ldots]$ But $[\ldots]$ a certain crucial breakage can take place between the violence by which we are formed and the violence with which, once formed, we conduct ourselves [...] The normative production of the subject is an iterable process -the norm is repeated, and in this sense is constantly "breaking" with the contexts delimited as the "conditions of production" (Butler, 2009: 167-168). [El énfasis es nuestro]

La traducción y apropiación de la realidad de la violencia en términos policiales y judiciales no solo refuerza la imagen de la mujer víctima necesitada de tutela y protección por parte del sistema sino que, además, obstaculiza la 
inteligibilidad y visibilización de cualquier instancia de agencia y empoderamiento (Butler, 1990; De Lauretis, 1989; Despentes, 2006; Halberstam, 2001; Sontag, 2003) que no coincida con la matriz coactiva construida, y legitimada, sobre la acción de denunciar. Un verdadero cambio ideológico (que ayude a transformar el problema de la violencia contra las mujeres) no puede ser llevado a cabo sin una reformulación de los discursos (Burkle y Reigada, 2006; Colaizzi, 1990; López Díez, 2005).

En el marco de las posibilidades que puede abrir la iterabilidad performativa constituida sobre la no violencia, Butler abunda sobre el concepto de mimesis y lo vincula con la reflexión spivakiana sobre el concepto de traducción/ representación como "apropiación" (Spivak, 1988) que señalamos más arriba. En ese sentido, Butler propone que la mimesis (entendida como representación/traducción de la realidad en términos de re-producción cultural) puede servir como herramienta con la que el/la "traductor/a" (llámase institución, agente judicial, medios o sujeto) ejerza un desplazamiento sobre cualquier representación original para desvelar la violencia cultural constitutiva e intrínseca con el objetivo de "[...] bring into relief the non-convergence of discourses [of collectivity] so that one might know through the very ruptures of narrativity the founding violences of an episteme" (Butler, 2000: 37). Esto abriría las puertas al trabajo que proponen López Díez (2004) y Burkle y Reigada (2006) de reinsertar en el marco de la teoría feminista el abordaje de la violencia machista.

En un trabajo anterior nos preguntábamos si podíamos construir procesos de identificación representacional que desvelaran la estructura fantasmática del patriarcado y permitieran exponer la inconsistencia y vulnerabilidad de la economía sexual que posibilita, a pesar de su inconsistencia, la violencia machista (Gámez Fuentes, 2010: 152). En esta ocasión, sin embargo, nos ha interesado indagar más allá en aras de un proyecto democrático en el que docentes, profesionales y medios se impliquen en la producción de representaciones, narrativas, debates y procesos que reactiven el contenido político de la violencia y no la presenten como aislada e individualizada. Concretamente, las estrategias que proponemos deberían pasar por:

- explorar vías narrativas de abordaje (y transformación) de la violencia (y el conflicto), más allá del ámbito de lo criminal y lo penal, a través de productos que muestren cómo las mujeres la sobreviven y afrontan de modos originales, personales y contextuales (sean o no tutelados);

- exponer los peligros y limitaciones que encierra el marco de reconocimiento construido sobre el "tutelaje" como solución a la violencia; 
- profundizar en los claroscuros que rodean la constitución subjetiva de la víctima, solo en tanto que denunciante, exponiendo la falacia de su soberanía en un contexto de violencia y ampliando el concepto de responsabilidad en la denuncia más allá de la figura de la víctima;

- ahondar en los mecanismos de dependencia entre víctima, comunidad y agresor para agotar todas las implicaciones éticas en el análisis de dónde reside la responsabilidad de la denuncia con respecto a la desigualdad estructural que limita la gestación del empoderamiento;

- articular qué tipo de responsabilidad e iniciativas debieran de poner en marcha los medios para exponer las perversas vinculaciones entre representaciones sexistas, desigualdad estructural y justificación implícita de la violencia;

- innovar en la creación de relatos que ayuden a desmontar patrones (aparentemente románticos pero estructuralmente lesivos) de establecimiento de relaciones de pareja;

- desvelar las relaciones entre violencia física, violencia cultural, representación e identidad de género a través de nuevos productos, formatos y enfoques informativos que descubran el legado cultural que ha intentado relegar a las mujeres a posiciones carentes de toda agencia y poder;

- diseñar acciones de sensibilización, más allá de la denuncia, que, por un lado, desmitifiquen, la supuesta contingencia de la violencia sufrida exponiendo, más bien, que dicha violencia es de carácter universal (ya que la violencia del maltratador viene sustentada por la sexuación social y la desigualdad estructural en base al género); y que, por otro lado, desplieguen la contingencia misma de la norma social del patriarcado en relación a su variabilidad dependiendo de marcos históricos, políticos y económicos determinados.

De este modo, a través de la innovación representacional alejada de los marcos de reconocimiento establecidos o, en palabras de Butler (siguiendo a Spivak), a través de una apropiación mimética desplazada, podríamos romper con la opacidad representacional y política que legitima unas vías de abordaje frente a otras. Esto abriría espacios narrativos que posibilitarían la activación del contenido político y de las limitaciones (y condicionantes) de la sujeción tecnológica (léase bio-política) que encierran las formas de abordaje actual de la violencia de género. Y, en definitiva, permitiría modos innovadores de pensar cómo ocupar los peligros inherentes a la inteligibilidad sujeta a la sexuacion social sin violencia. 


\section{BIBLIOGRAFÍA}

Adelman, M. (2009). "Domestic Violence". En P. Essed, D. T. Goldberg y A. Kobayashi (eds.), A Companion to Gender Studies. Oxford: Wiley-Blackwell.

Andrijasevic, R. (2007). "Beautiful Dead Bodies: Gender, Migration and Representation in Anti-trafficking Campaigns". feminist review, 86, 22-44.

Aran Ramspott, S. y Medina Bravo, P. (2006). "Representación de la violencia doméstica en la prensa española". Estudios sobre el mensaje periodístico, 12, 9-25.

Bach, M., Altés, E., Gallego, J., Plujá, M. y Puig, M. (2000). El sexo de la noticia: reflexiones sobre el género en la información y recomendaciones de estilo. Barcelona: Icaria.

Belando Garín, B. y Montiel Roig, G. (Coords.) (2011). Contenidos y mercado en la regulación de la Comunicación Audiovisual. El nuevo marco normativo de la Ley 7/2010 General de Comunicación Audiovisual. Valencia: Tirant lo Blanch.

Benet, V. (2007). "Reimaginar el frente: la retórica cinematográfica del pacifismo". Archivos de la Filmoteca, 55, 12-39.

Bengoechea, M. (Coord.) (2010). Efectos de las políticas lingüísticas, antisexistas y feminización del lenguaje en los medios. Madrid: Instituto de la Mujer (Ministerio de Sanidad, Política Social e Igualdad).

Berganza Conde, M. R. (2003). "La construcción mediática de la violencia contra las mujeres desde la Teoría del Enfoque". Comunicación y Sociedad, 16(2), 9-32.

Bosch-Fiol, E. y Ferrer-Pérez, V. A. (2012). "Nuevo mapa de los mitos sobre la violencia de género en el siglo XXI". Psicothema, 24(4), 548-554.

Brändle, G., Cárdaba, M. A. y Ruiz, J. A. (2011). "Riesgo de aparición del efecto boomerang en las comunicaciones contra la violencia". Comunicar, 37(19), 161-168.

Brea, J. L. (2005). Estudios visuales. La epistemología de la visualidad en la era de la globalización. Madrid: Akal.

Burkle, M. y Reigada, A. (2006). "Teoría crítica feminista y comunicación”. Redes.com, 3, 11-16.

Butler, J. (1990). Gender Trouble. London: Routledge.

Butler, J. (2000). "Restaging the Universal: Hegemony and the Limits of Formalism".

En J. Butler, E. Laclau y S. Žižek, Contingency, Hegemony, Universality: Contemporary

Dialogues on the Left. New York y London: Verso, 11-43.

Butler, J. (2008). "Gender is Extramoral." Interview with Judith Butler. Judith Butler and Fina Birulés (Interviewer), Centre de Cultura Contemporània, Barcelona. Accesible en: http://www.egs.edu/faculty/judith-butler/articles/gender-is-extramoral/ [Fecha de consulta: 5 de mayo de 2011].

Butler, J. (2009). Frames of War: When is Life Grievable? New York y London: Verso.

Capella, M. L., Hill, R. P., Rapp, J. M. y Kees, J. (2010). "The Impact of Violence against Women in Advertisements". Journal of Advertising, 39(4), 37-51.

Casado Aparicio, E. y García García, A. A. (2006). "Violencia de género: dinámicas identitarias y de reconocimiento". En F. J. García Selgas y C. Romero Bachiller (Eds.), El doble filo de la navaja: violencia y representación. Madrid: Trotta, 89-106. 
Castillo, A. y Carretón, M. C. (2010). "Investigación en comunicación. Estudio bibliométrico de las revistas de comunicación en España”. Comunicación y Sociedad, 23(2), 289-327.

Colaizzi, G. (1990). "Feminismo y teoría del discurso: razones para un debate". En G. Colaizzi (Ed.), Feminismo y teoría del discurso. Madrid: Cátedra, 13-28.

De Lauretis, T. (1984). Alice Doesn't: Feminism, Semiotics, Cinema. Bloomington: Indiana University Press.

De Lauretis, T. (1989). "The Violence of Rhetoric: Considerations on Representation and Gender". En N. Armstrong y L. Tennenhouse (Eds.), The Violence of Representation. London y New York: Routledge, 239-259.

De Miguel Álvarez, A. (2003). "El movimiento feminista y la construcción de marcos de interpretación: el caso de la violencia contra las mujeres". Revista Internacional de Sociología, 35(mayo), 127-150.

División para el Adelanto de la Mujer (DAW)-Departamento de Asuntos Económicos y Sociales (2010). Manual de legislación sobre la violencia contra las mujeres. New York: Naciones Unidas.

Fagoaga, C. (1994). "Comunicando violencia contra las mujeres". Estudios sobre el mensaje periodístico, 1, 67-90.

Fagoaga, C. (1999). La violencia en medios de comunicación: maltrato en la pareja y agresión sexuada. Madrid: Dirección General de la Mujer.

Fagoaga, C. y Secanella, P. (1986). Umbral de presencia de las mujeres en la prensa española. Madrid: Instituto de la Mujer.

Fernández Arribas, J. y Noblejas, M. (eds.) (2010). Cómo informar sobre violencia contra la mujer en las relaciones de pareja. Madrid: Centro Reina Sofía

Fernández Díaz, Natalia (2003). La violencia sexual y su representación en la prensa. Barcelona: Anthropos.

Fernández-Villanueva, C., Revilla-Castro, J. C., Domínguez-Bilbao, R., Gimeno-Jiménez, L. y Almagro, A. (2009). "Gender Differences in the Representation of Violence on Spanish Television: Should Women Be more Violent?”. Sex Roles, 61, 85-100.

Fernández Romero, D. (2008). "Gramáticas de publicidad sobre la violencia: la ausencia del empoderamiento tras el ojo morado y la sonrisa serena". Feminismo/s, 11, 15-39.

Fonseca, S. (2010). "Casos de triste recuerdo". En J. Fernández Arribas y M. Noblejas (Eds.), Cómo informar sobre violencia contra la mujer en las relaciones de pareja. Madrid: Centro Reina Sofía, 97-111.

Foucault, M. (1979). Discipline and Punish: The Birth of the Prison. Harmondsworth: Penguin.

Foucault, M. (1980). Power/Knowledge: Selected Interviews and Other Writings, 19721977, London: Harvester.

Foucault, M. (1981). The History of Sexuality, Vol. 1. Harmondsworth: Penguin.

Gallego, J. (1990). Mujeres de papel. De ¡Hola! a Vogue: La prensa femenina en la actualidad. Barcelona: Icaria. 
Gámez Fuentes, M. J. (2007). "Algunes apuntes sobre la representación de la violencia de género en el cine”. En J. Marzal Felici y F. J. Gómez Tarín (Eds.), Metodologías para el análisis de la imagen fílmica. Madrid: Edipo, 241-250.

Gámez Fuentes, M. J. (2009). "Medios de comunicación y violencia de género: paradojas y vías de desarrollo”. En J. M. Bernardo, E. Martínez y G. Montiel (Coords.), Retos de la comunicación ante la violencia de género. Marco jurídico, discurso mediático y compromiso social. Valencia: Tirant lo Blanch, 139-156.

Gámez Fuentes, M. J. (2010). "La comunicación desde la perspectiva de género". En I. Comins Mingol y S. París Albert (Eds.), Investigación para la paz. Barcelona: Icaria.

Gámez Fuentes, M. J. y Blázquez Chaves, E. (2005). "Mujeres y publicidad: de la representación de la violencia a la violencia de la representación". En R. López, J. Marzal y F. J. Gómez (Eds.), El análisis de la imagen fotográfica. Castellón: Universitat Jaume I.

García Meseguer, A. (1977). Lenguaje y discriminación sexual. Barcelona: Montesinos.

Gil Calvo, E. (2003). El miedo es el mensaje. Madrid: Alianza.

Halberstam, J. (2001). "Imagined Violence/Queer Violence: Representations of Rage and Resistance". En M. McCaughey y N. King (Eds.), Reel Knockouts. Violent Women in the Movies. Austin: University of Texas Press, 244-266.

Haraway, D. (1991). Ciencia, cyborgs y mujeres: la reinvención de la naturaleza. Madrid: Cátedra.

Herrera Enríquez, M. C. y Expósito, F. (2009). "Responsabilidad compartida: influencia de los medios de comunicación en la atribución de culpabilidad y justificación de la violencia de género". Anuario de psicología jurídica, 19, 103-110.

Imbert, G. (1982). Elena Francis, un consultorio para la transición. Barcelona: Península.

Lee, M. J., Hust, S., Zhang, L. y Zhang, Y. (2011). "Effects of Violence against Women in Popular Crime Dramas on Viewers' Attitudes related to Sexual Violence". Mass Communication and Society, 14(1), 25-44.

López Díez, P. (2001). Representación de género en los informativos de radio y televisión. Madrid: Instituto de la mujer y Instituto Oficial de Radio Televisión Española (IORTV).

López Díez, P. (2004). "La mujer, las mujeres y el sujeto del feminismo en los medios de comunicación”. En P. López Díez (Ed.), Manual de información en género. Madrid: IORTVE e Instituto de la Mujer. Accesible en: www.pilarlopezdiez.eu/pdf/Mujer MujeresSujetoFem.pdf [Fecha de consulta: 2 de julio de 2012].

López Díez, P. (2005). "Los desafíos y la experiencia docente en el campo de los estudios universitario de género y comunicación". En V. Maquieira et al. (Eds.), Democracia, feminismo y universidad en el siglo XXI. Madrid: Universidad Autónoma.

López Díez, P. (2008). "Los medios y la representación de género: algunas propuestas para avanzar". Feminismo/s, 11, 95-108.

López Díez, P. (Dir.) (2006). Representación de la violencia de género en los informativos de TVE. Madrid: IORTVE e Instituto de la Mujer. 
Lorente Acosta, M. (2008). "El agresor de género: acciones y reacciones del posmachismo". En La igualdad no es una utopía. X Congreso internacional e interdisciplinar Mundos de Mujeres/Women's Worlds 2008. Madrid: UCM, 162-177.

Loscertales, F., Fernández, E. e Higazi, Z. (2009). "Violencia contras las mujeres en los medios de comunicación. Un estudio en los informativos de TVE". Pixel-Bit. Revista de Medios y Educación, 34(enero), 121-134.

McQuail, D. (1987). Introducción a la teoría de los medios de comunicación de masas. Barcelona: Paidós.

Magallón, C. (2006). "Paz en femenino". Revista Fusión, noviembre. Accesible en: http:// www.revistafusion.com/2006/noviembre/entrev158-2.htm [Fecha de consulta 15 de febrero de 2010].

Marín, F., Armentia, J. I. y Caminos, J. (2011). "El tratamiento informativo de las víctimas de violencia de género en Euskadi: Deia, El Correo, El País y Gara (20022009)". Comunicación y Sociedad, 24(2), 435-466.

Martín Serrano, M. y Martín Serrano, E. (Coords.) (1995). Las mujeres y la publicidad. Nosotras y vosotros según nos ve latTelevisión. Madrid: Instituto de la Mujer.

Martínez Guzman, V. (2010). "Nuevas masculinidades y cultura de paz". En M. E. Díez Jorge y M. Sánchez Romero (Eds.), Género y paz. Barcelona: Icaria, 291-313.

Martínez Nicolás, M. y Saperas Lapiedra, E. (2011). "La investigación sobre comunicación en España. Análisis de los artículos publicados en revistas científicas". Revista Latina de Comunicación Social, 66, 101-129.

Matterlart, A. (1994). La comunicación-mundo. Madrid: Fundesco.

Menéndez Menéndez, M. I. (2010). Representación mediática de la violencia de género. Análisis de la prensa balear (2004-2008). Palma de Mallorca: Edicions UIB.

Mirzoeff, N. (1999). An introduction to visual culture. London: Routledge.

Montiel Roig, G. (2009). “¿Qué contenidos generan violencia y desigualdad de género? Una aproximación a la regulación y autorregulación de los medios de comunicación”. En J. M. Bernardo, E. Martínez y G. Montiel (Eds.), Retos de la comunicación ante la violencia de género. Marco jurídico, discurso mediático y compromiso social, Valencia: Tirant lo Blanch, 115-136.

Nogueira, Ch. y Sahuquillo, M. R. (2011). “¿Violencia de qué?”. El País [edición digital]. Accesible en: http://www.elpais.com/articulo/sociedad/Violencia/elpepisoc/ 20110408elpepisoc_1/Tes. [Fecha de consulta: 13 de abril de 2011]

Osborne, R. (2008). "De la 'violencia' (de género) a las 'cifras de la violencia': una cuestión política”. Empiria. Revista de Metodología de Ciencias Sociales, 15(enerojunio), 99-124.

Peñamarín, C. y Frabetti, C. (1994). La mujer en la publicidad. Madrid: Instituto de la Mujer.

Peñamarín, C. y López Díez, P. (Coords.) (1995). Los melodramas televisivos y la cultura sentimental. Madrid: UCM y Dirección General de la Mujer de la Comunidad Autónoma de Madrid

Preciado, B. (2002). Manifiesto contra-sexual. Barcelona: Opera Prima. 
Quílez, R. (2004). "El sector publicitario contrario a que la Ley de Violencia de Género controle los contenidos". El Mundo [edición digital]. Accesible en: http://www. elmundo.es/elmundo/2004/06/01/comunicacion/1086099402.html [Fecha de consulta: 20 de junio de 2004].

Schmal, N. y Camps, P. (2008). "Repensando la relación entre la ley y la violencia hacia las mujeres. Una aproximación a los discursos de los/las agentes del ámbito judicial en relación a la ley integral de violencia de género en España”. Psicoperspectivas, $7,32-58$.

Sontag, S. (2003). Ante el dolor de los demás. Madrid: Alfaguara

Spivak, G. Ch. (1988). “Can the Subaltern Speak?”. En C. Nelson y L. Grossberg (Eds.), Marxism and the Interpretation of Culture. Urbana: University of Illinois Press, 271-313.

Valor-Segura, I., Expósito, F. y Moya, M. (2011). "Victim Blaming and Exoneration of the Perpetrator in Domestic Violence: the Role of Beliefs in a Just World and Ambivalent Sexism". The Spanish Journal of Psychology, 14(1), 195-206.

Vives-Cases, C. y La Parra Casado, D. (2008). "Spanish Politicians Discourse about the Responses to Violence against Women". Gaceta Sanitaria, 22(5), 451-456.

VVAA (2010), Integración de la perspectiva de género y las enseñanzas en materia de igualdad de mujeres y hombres y no discriminación en los planes de estudio de grado de la Universitat Jaume I. Informe de situación, Castellón: Unidad de Igualdad y Fundación Isonomía, Universitat Jaume I. Accesible en:

http://www.uji.es/bin/organs/ui/docs/diagnostico.pdf [Fecha de consulta: 8 de septiembre de 2012].

MARÍA JOSÉ GÁMEZ FUENTES es máster y doctora en Teoría Crítica y Estudios Culturales por la Universidad de Nottingham (Reino Unido), donde trabajó también como profesora. En la actualidad es titular del departamento de Ciencias de la Comunicación de la Universitat Jaume I de Castellón y secretaria del Instituto Interuniversitario de Desarrollo Social y Paz y miembro del Instituto de Investigaciones Feministas y de Género de dicha universidad. Imparte docencia sobre comunicación, igualdad y violencia a nivel de grado y postgrado. Sus investigaciones abordan el análisis y transformación de la producción mediática desde una perspectiva cultural y de género. 